\title{
Embodied versus disembodied information: How online artifacts influence offline interpersonal interactions
}

\author{
Xiaoli Tian \\ Department of Sociology \\ University of Hong Kong
}

For citation:

Tian, Xiaoli. 2017. "Embodied versus disembodied information: How online artifacts influence offline interpersonal interaction.” Symbolic Interaction. Online first:

http://onlinelibrary.wiley.com/doi/10.1002/symb.278/full

\begin{abstract}
:
This paper examines how the sheer volume of personal information recorded and searchable online (online artifacts) has transformed the situated activity system central to Goffman’s dramaturgical theories. In-depth interviews reveal that individuals believe disembodied information based on online artifacts is a more accurate representation of others than embodied information from spatially and temporally bounded face-to-face processes because they represent how others have behaved over time and are attested by their online contacts. However, the $n$-adic structure of online interaction leads to mismatched expectations about whether disembodied information is taken into account during face-to-face encounters, and consequently can result in embarrassment.
\end{abstract}


Keywords: Disembodied information, Interaction order, Embarrassment, Social Media, China

While in traditional society we interacted with acquaintances, in modern society, we frequently interact with strangers or semi-strangers (Simmel 1971; Tönnies 1963). As a result, we have little information about the "others” who are our interactants in urban/modern settings, leading to uncertainty about how to behave. This feature of interpersonal interaction in modern societies has been captured by Goffman, who mainly focused on interactions with strangers in public and semi-public settings. In his theatrical metaphor of interaction, Goffman (1959) noted that it is essential for participants in an interaction to acquire information about each other so they can define the situation and decide on the right moves. While impression management is about information that actors give and give off, it is also about the volume and type of information that the actors are able to obtain about other participants. During face-to-face (FTF) interactions, judgments are made by relying on either past experience with others (for example, acquaintances) or on mannerism and appearance (in the case of strangers) in spatially and temporally bounded contexts (Goffman 1959: 13). Goffman provided a compelling account of performance during FTF interactions; however, he focused on the embodied information found in a physically bounded context. Goffman was not concerned with disembodied information such as that which "we receive from letters and mailed gifts... [which] require that the organism do something that traps and holds information long after the organism has stopped informing” (Goffman 1963: 14)(see also Giddens 1987).

Today, internet interactions, especially those on social media, leave behind significant amounts of disembodied personal information in the form of recorded and searchable data which 
are available to a large audience. To quote from Hogan (2010), personal data found on social media are online "artifacts" that are derived from past performances and exhibitions online. Online technology now affords access to more disembodied information. It is not uncommon to check the online information of others prior to a specific physical FTF interaction (Westerman et al. 2008). As a result, online artifacts have transformed the situated activity system that is central to Goffman's dramaturgical theories. How does the increase in disembodied information about others influence the dynamics of FTF interactions?

To explore how online artifacts influence offline interpersonal interactions, I draw on indepth interviews with Mainland Chinese students who are born and raised in Mainland China but attend Hong Kong universities for their undergraduate studies. ${ }^{1}$ Like their Western counterparts, they actively use social media to connect with others, present themselves, and maintain identities. They frequently interact both online and offline with their Mainland counterparts at the same university (Tian 2016). This results in significant overlap between their online and offline networks. Therefore, these students are ideal subjects for examining how online artifacts influence offline social interactions.

The findings reveal that these students believe online artifacts are more accurate and authentic representations of others than cues obtained in spatially and temporally bounded FTF processes because they represent how others have previously behaved, and those artifacts are attested by their online contacts. Moreover, personal information potentially hidden during FTF interactions is made available to interactants prior to a specific offline encounter. This disembodied information from online platforms gives them a sense of control and reduced

\footnotetext{
${ }^{1}$ Universities in Hong Kong have accepted students from Mainland China since 1997. By AY 2013-2014, the numberof Mainland students in Hong Kong had increased to 6,521 undergraduates and 4,767 postgraduates (UGC Statistics).
} 
uncertainty during FTF encounters. However, due to then-adic organization of online interaction (Tian and Menchik 2016), individuals have different levels of awareness of whether others have taken online artifacts into account during specific offline encounters. This leads to mismatched expectations about what interactants may know about each other, which can result in embarrassment during FTF encounters.

This article contributes to the existing literature in three ways. First, most existing social media studies focus on how people present themselves or construct identities by using online platforms (Zhao 2005, Zhao et al. 2008, Robinson 2007), but this paper examines how information disclosed online influences offline FTF interactions. Easy access to disembodied information that is outside the physically and temporally bounded context means that FTF interactions are now disembodied from the local context. Second, this paper shows that while online users are afforded more means to obtain information about others, new sources of uncertainties are simultaneously created by the unique structure of online interaction during which the others are undetectable. Third, extant studies on social media and interaction have focused on Western contexts, but this study examines Chinese university students in Hong Kong who are located in unique social and cultural contexts.

In the following, I will first discuss Goffman’s theories on impression management, information, and interaction. Then, I will introduce the conceptualization of online data as “artifacts”, followed by a brief review of the relevant literature on identity and online interactions. After providing the data and methods, I will then turn to how personal artifact information on social media facilitates interpersonal interaction between students by seemingly providing a greater sense of control during FTF encounters. I discuss how the increase of disembodied information has changed the dynamics of FTF interpersonal encounters, and how 
the consequences are embedded in the broader social context, such as the recent conflicts between Mainland China and Hong Kong. However, due to the unique nature of $n$-adic interaction online, the interactants still have unmatched expectations about what is shared with whom, and at what time. These unmatched expectations thus lead to disruptions of the interaction order. In conclusion, I discuss the various consequences of increasing access to ordinary people’s online artifacts.

\section{DISEMBODIED INFORMATION AND INTERACTIONS}

To describe how an individual presents him/herself to others to establish an idealized self, Goffman used a theatrical metaphor that considers life as a stage on which individuals put on performances. During their performances, individuals try to influence other participants (the audience) during a period marked by their continuous presence (Goffman 1959: 15).Goffman (1963) defined the social setting of an interaction during which individuals put on performances as a "situation”, which refers to a "full spatial environment" (p. 18) of signals and informationintentionally designed or unwittingly given — to help actors produce and comprehend meanings.

During FTF interactions, individuals try to acquire information about each other to define the situation, including physical appearance, general socio-economic status, etc. (Goffman 1959: 13). The amount and nature of the information are vital because they affect decisions on how best to act so as to ensure a smooth interaction with desirable outcomes (Goffman1959: 21). Goffman dubbed the information that individuals give and give off during interactions as “embodied information”, i.e., messages “that a sender conveys by means of his (her) own current bodily activity” (1963: 14). While he acknowledged the presence of “disembodied information”, 
i.e. messages obtained through other channels outside the current context, he failed to elaborate on the volume and nature of this information.

Today, there are many more means to seek information about others because of the Internet, and especially social media, which has showcased personal lives to a much wider audience. The world is therefore not only a stage but also an online gallery of "artifacts" of recorded data from past and current lives (Hogan 2010).

Actively searching for online artifacts even before meeting in person changes the main interactional dynamics described by Goffman. According to Goffman, total strangers rely on clues from appearance and demeanor (or personal front, per Goffman (1961), then draw upon past experiences with individuals who are somewhat similar or in a comparable social setting to predict possible behaviors. If the other person is an acquaintance, the actor relies on previous judgment of their traits or personalities to infer their response (Goffman 1959: 13). Since inferences about others are based on existing information, online artifacts can help turn strangers into acquaintances.

However, today's access to online artifacts allows actors to easily achieve what Goffman called “cognitive recognition” of others (1963:113) without directly engaging with anyone. According to Hall et al. (2014), strangers can accurately gauge the self-reported personality of profile owners by reading their Facebook contents. Similarly, online users do not differentiate between their online and real-world identities (Maloney2013). Thus, online personal information allows judgments to be made prior to interpersonal interactions. In many instances, online profile owners are unaware of who has viewed their personal information or when it was viewed. It is therefore interesting to determine whether prior engagements with online personal data of other 
people — i.e. disembodied information obtained outside of the immediate interactional contextinfluence the dynamics of current interactions.

\section{IDENTITY, EMBARRASSMENT, AND ONLINE INTERACTIONS}

In discussing the importance of acquiring information about others to realize interpersonal interactions, Goffman was also concerned with the disruption of the interaction order, and in particular, embarrassment (Goffman 1959: 266; Heath 1988: 137), which occurs when one presents a self that is not supported by others (see also Gardner and Gronfein 2005).Because embarrassment is caused by inconsistent selves, it is more common when individuals attempt to simultaneously manage multiple selves, which is now more challenging with the frequent use of social media because discrepancies arise between online and offline presentations of the selves.

Despite the ability to present the ideal or more authentic selves online, new media increases uncertainties about who sees the information (Zimmer and Hoffman 2011). Social media amalgamates different audiences made up of individuals from various networks, resulting in “context collapse” (boyd 2008; Marwick and boyd 2011; Davis and Jurgenson 2014). In other words, while it seems that individuals are empowered with more choices, there is simultaneously the risk of loss of control over personal information disclosed online (Belk 2013, p. 483). The creation and circulation of online personal information may quickly spiral out of control (Belk 2013), and be disseminated well beyond the original intended audience, which constitutes the breakdown of the "contextual integrity" of the information disclosed (Zimmer and Hoffman 2011).

While these are important aspects of loss of control in the digital era, two questions remain unanswered. First, how do online artifacts influence offline interactions? Second, could the 
problems of sharing information with unintended others be solved if users are aware of the problem and only share information that could be shared with "anyone”? Indeed, according to existing empirical research, most social media users maintain a relatively accurate selfpresentation (Vazire and Gosling 2004; Gosling et al. 2011; Davis 2014), especially because self-misrepresentation may be challenged by offline friends who are also online. Their awareness of online context collapse means that they will strategize to maintain a consistent self (Debatin et al.2009; Davis 2014).

Even though social media users try to create and maintain authentic and consistent selves across both online and offline interactions, users still encounter inherent problems because the structure of online interaction with undetectable others is essentially different from that of offline interaction. Tian and Menchik (2016) argued that online interactions with undetectable others are " $n$-adic" in nature, in that $n$-adic utterances are directed towards a non-unified audience whose invisibility conceals their exact number in an interactional venue or the time that they enter or exit an interaction. In fact, anyone may enter the conversation long after the disclosure has been made. Without a physical co-presence, individuals can only mentally construct their potential audience when determining how information is shared (Marwick and boyd 2011; Litt 2012). This "imagined audience" often bears no resemblance to the actual audience. Therefore, an online post could involve unsolicited observers (Marwick and boyd 2014), which could lead to inconsistent presentations of the self.

In an $n$-adic interaction, awareness of multiple audiences is contingent on encounters that evolve over time, and driven by the feedback loop in interactions. Online disclosers usually start with a vague awareness of the public nature of their postings. Over time, they develop a "chorus," or regular respondents to whom they begin to direct their postings; in turn, members of the 
chorus provide ongoing commentaries. Soon, the users feel a sense of intimacy and begin to share private information. Eventually, they may receive unexpected comments from silent observers or audience members who are “influential outsiders” (Tian and Menchik 2016); "influential” because they are important contacts, but "outsiders" in that they were not taken into account during posting. Afterwards, the online users may feel that they have presented themselves in an unflattering manner so they change the privacy settings or disclose less or differently. The process by which they gradually become aware of these multiple audiences is illustrated in Figure 1.

$<$ Figure 1 here $>$

The unique structure of $n$-adic interactions has two main implications for social relationships that span online and offline interactions: the ambiguity of the number of audience members, and the time elapsed between viewing the online artifacts and actual offline encounters. How this unique $n$-adic structure and the sheer volume of online artifacts transform the interaction order of FTF encounters will be the focus of this study.

\section{DATA AND METHODS}

To examine how online artifacts influence offline interactions, I focus here on university students in Hong Kong. The data presented in this paper are part of a larger project on social media use among university students in Hong Kong. The data collection took place from October 2012 to December 2015. I mainly examined three different social media: Renren, WeChat, and Facebook. In 2012, the most popular social media site among Mainland Chinese students was Renren, followed by Facebook. In the second half of 2013, WeChat use began to overtake Renren, while Facebook remained second in popularity. WeChat combines some of the features of Facebook in terms of personal data sharing with instant messaging (IM) between individuals 
and in groups. The most important function is Moments, which is regularly used by $76.4 \%$ of the subscribers. ${ }^{2}$ Moments allows sharing all kinds of information with contacts and responding with a "Like" or a comment.

The purpose of the larger study was to understand how the two social groups of Mainland Chinese and local Hong Kong students use social media differently, and the consequences for offline relationships. I conducted interviews, online and offline observations, as well as content analysis of their online disclosures. In this study, data are drawn from interviews with only Mainland Chinese students enrolled in three specific universities in Hong Kong because they vary in the size of their Mainland Chinese student communities and the organization of university life.

Findings from the larger project reveal that the Mainland students in Hong Kong are very academically competitive due to the need for high marks in order to be enrolled at universities in Hong Kong. The Mainland students in Hong Kong also pay much higher tuition than students in Mainland China and local students in Hong Kong. As such, the Mainland students in Hong Kong are usually from financially well-off, middle-class families in urban China. They tend to form a very close community with other Mainland students attending the same university both online and offline. The closeness of their community and recent discrimination from the Hong KongMainland conflicts fuel their competitive nature in both academics and job placement after graduation. They also care a lot about their relative status compared to other students, and try to maintain good relationships with others.

I recruited 58 Mainland Chinese undergraduate students (30 females and 28 males) from these three universities by using a nonrandom quota sampling method. The participants were

${ }^{2}$ http://technode.com/2015/01/22/WeChat-reaches-1-1b-registered-accounts-440m-mau/, accessed Oct. 2, 2015 
selected by both public recruitment efforts and working with university administrative offices to recruit students of diverse backgrounds. The non-random sampling of the interviews was driven by theoretical assumptions. They were selected to represent the widest differences in their socialbiographical situations and personal networks (both online and offline). The interviewees included students of various academic disciplines with various levels of participation in student associations. All used Renren and Facebook before 2013, and after 2013, WeChat and Facebook. During the interviews, I asked the students how the use of social media influences their interpersonal interactions offline with different sectors of their personal social networks. The interview questions covered basic demographic information, social network composition, online activities, daily routines of university life (both on- and off-campus) and social activities. A detailed picture was thus obtained of how the respondents make and view postings on social media, how they maintain self-images online and offline, and how information obtained from social media influences their offline interactions with others. Special attention was given to interaction details such as the strategies used when interacting with different others, overcoming interaction barriers, etc. I also asked about their political views, especially in terms of the recent Hong Kong-Mainland China conflicts. ${ }^{3}$ In addition, I asked for elaborations on their most memorable interactions. Attention was paid to how they explained episodes of online and offline encounters (breaches) with influential outsiders. The interactional details allow for a general analysis of the relationship between user perception of audiences, consideration of relationships, and the type of information disclosed or obtained. Their responses usually involved interactions

\footnotetext{
${ }^{3}$ Indeed, nearly 17 years after thereturnof Hong Kong to China, tensions between Hong Kong and Mainland China are still mounting (Tharoor 2014; Lai 2012). These tensions are reflected in local media and messages on Facebook, and have resulted in various protests against Mainlanders (Chow 2012). Many of these protests are organized or facilitated through social media. In 2015, the political tension was highlighted in the Occupy Central Movement (also known as the Umbrella Movement in Hong Kong) in which university students were important players.
} 
that ended with emotional discomfort or embarrassment. Focusing on conflicts allowed elucidation of the assumptions that underlie social interaction (Emerson 2015).

The interviews were conducted in private office spaces on the university campuses to ensure privacy, or occasionally in a public space like a coffee shop, if that was the preference of the respondent. They were conducted in Mandarin Chinese and transcribed by two research assistants. Coding was conducted on the original Chinese text by the author. All of the quotes were translated into English by the author.

The interview data were complemented with online and offline observations. From October 2011 onwards, I conducted online observations on Renren and Facebook, and then since 2013, WeChat and Facebook. I asked for permission to add about 10 of the respondents as contacts so that I could observe their online activities on a daily basis. The interview data and online ethnographic information provided an understanding of both the online self-presentation style of the respondents in the broader context of the specific online platform as well as the underlying reasons for their online behavior. In addition, from October 2012 to September 2015, I conducted offline observations on the campuses, noting how students interacted with each other in various public spaces. I also made multiple visits to the residential halls to ask students about hall life and their daily interactive activities. During observations, I relied on my positional knowledge to better understand the circumstances (Ellis 1995; Denzin 2001). From the online and offline observations, I gained awareness that online disclosures are not only a means of presentation, but also lead to substantial changes in offline encounters.

I used both abductive analysis (Timmermans and Tavory 2012) and analytic induction (Goldenberg 1993; Katz 2001) to produce explanations. Abductive analysis allows insights from the literature (existing theories), and new concepts to be developed in order to account for 
puzzling empirical findings. Current theoretical ideas on online disclosures, such as "context collapse” (boyd 2008), “contextual integrity” (Nissenbaum 2010) and “n-adic interaction” (Tian and Menchik 2016) are used as the tentative analytic frameworks, which summarize theoretical establishments on empirical phenomena, and isolate puzzling events. To avoid essentializing current categorizations (Murphy and Dingwall 2003), I verified the research findings against the analytic frameworks and found that surprisingly, even when the students assumed that they shared with everyone on their online contact list, they still encountered breaches offline. Then, I used analytic induction to identify similarities to develop new concepts or ideas (Ragin and Amoroso 2010), such as mismatched expectations on online artifacts between profile owners and influential outsiders.

While existing literature focuses on the strategies used to present their online selves, I focus instead on how their access to the online artifacts of others, or how others view their own online artifacts, influences their offline FTF encounters. The findings reveal that while users tend to believe that online artifacts facilitate offline interactions, there are also unintended consequences, as I will discuss below.

\section{BEING AUTHENTIC: NOW AND HERE VERSUS ALWAYS THERE}

The respondents were active users of at least one type of social media, and spent thirty minutes to four hours on social media daily. The majority lurked more than posted because they were aware that their posts and profiles reflected their identity and others might view them to obtain personal information. Consistent with existing studies on social media users in the West (Davis 2014), the respondents knew the importance of online artifacts and used various strategies to maintain an authentic self. 
However, the respondents also actively sought and used the online personal information of others to make judgments and form their own impressions. They believed that online artifacts could be used to make reliable judgments about the "real" motives, identities, and attitudes of others, and to facilitate offline interactions because online artifacts help overcame the spatial and temporal barriers of offline FTF interactions, and revealed information that was usually hidden in specific FTF encounters.

Overcoming spatial and temporal barriers

The respondents felt that online artifacts overcame the spatial and temporal barriers of offline FTF interactions in a few ways. First, they helped initiate offline relationships. Most of the respondents were informed about the usefulness of Renren or WeChat in cultivating social networks in university life, so after they were admitted or even before they physically arrived in Hong Kong, they found and added current students as their online contacts. They would be accepted as long as they identified themselves as a student of the same university. The respondents felt that this approach would be a good start to developing offline relationships and that even prior to physical meetings, early impressions could be made.

I usually added someone if we have friends in common, even if I don't know that person. Quite frequently, we would meet in person later. I would say to him/her, 'Oh...I know you from Renren'. The most important function of Renren... is that I found others who are also at the same university before I even met them in person. I found many more friends that way than if I physically met them in person. (Mainland interview 43, female) 
Second, the respondents admitted that they used the disembodied information from active searches and passive newsfeeds to judge how others might behave in real life, making it easier to gauge the attitudes, orientations, and interests of others. Consequently, they felt that it was easier to decide how to behave in FTF encounters.

I have many friends that I don’t know very well offline, but then through their posts and comments online, we formed a good impression of each other. If I liked what they wrote online, I'd want to be friends with them. Also, if I see them in person, I'd tell them, 'I read your article'. It's easier to start a conversation that way. Also, if someone has a common interest...then you can chat about that online and continue the conversation in real life...(and) bond that way. (Mainland interview 12, male)

Thus, online artifacts provided some basic information to the students in this study before they met in person. Most considered that this prior information facilitated their offline interaction, which echoes previous research that early impressions are formed through some form of digital mediation (Utz 2010), such as using social media to gather information about new acquaintances (Westerman et al. 2008).

Information from online artifacts could be the byproducts of online activity, such as online activity streams like news feeds, but some of the respondents also admitted that they intentionally search.

After I meet a new person and I want to find out more about them, I search for them on Google, Facebook or Renren. I find pictures...[and] sometimes I look at the comments of other people.... That way, I find out whether they're in a relationship, their hobbies, if 
they've won awards, and other stuff. I get a pretty good picture of them after searching online. (Mainland interview 11, male)

Many indicated that an online search was imperative before they decided whether to establish a friendship or how they proceeded in a relationship with an individual. These findings show that access and exposure to online artifacts have substantial impacts on offline performance and change perceptions. In fact, other studies have also pointed out that virtual experiences can impact offline behavior. Yee et al. (2009), for example, found that individuals behave differently even after some exposure in a virtual environment.

Additionally, the respondents pointed out that online artifacts were especially helpful for reacquainting old friends. The respondents indicated that since everyone's life changed fast, status updates on social media provided insight on appropriate topics and those that should be avoided. Access to online artifacts helped reduce potential uncertainty during FTF interaction. When uncertainty was reduced, the actors became more attractive and relationships were nurtured (see also Berger and Calabrese 1975).

I think social media updates help with my real life relationships. Like I know this guy who is from the Hui minority in China. In the past, he never said he was a Muslim. But recently, he posted a lot of information about Muslims. He also said (on WeChat Moments) that he only listens to Muslim music. I rarely see him on campus...But I saw from his updates that he is a Muslim. So if I see him in person now, I wouldn’t say anything about Muslims that might insult him. (Mainland interview 55, female) 
Online artifacts also helped these students compensate for infrequent offline encounters by creating a "co-presence" per Campos-Castillo and Hitlin (2013), i.e. "the perception of mutual entrainment between actors” (169), despite their lack of shared physical space.

Almost all of the respondents believed that the information shared during FTF interactions was limited because it was constrained by the immediate context and the preexisting relationship. Indeed, during FTF encounters, accessible sources of information are limited, especially for those who do not know each other or have not seen each other in a while because facts that are crucial to the FTF context, such as "real" attitudes and feelings, are often available only outside the time and place of interaction (Goffman 1959:13-14, 241).

I think information on social media helps me to understand others better. Like when we meet in person, it's normal to talk about school and jobs. Then we go from jobs to some other topics like where you live. But we can't go from where you live to the movie that you watched last night because you can't randomly change the topic. And not everybody can find stuff to talk about. So information exchanged and shared in person is limited compared to information available on social media, especially if the person is always online. The profile on Renren or Facebook gives you a better idea of what that person is like. (Mainland interview 3, male)

This respondent reflected that he could form a more comprehensive understanding of others based on online artifacts because the information shared in any specific FTF encounter was limited by the situation. This is consistent with existing research in terms of the disinhibition and confessional effects of online disclosures (Zhao 2005; Belk 2013): there is more personal information available online than offline. 
In sum, the respondents felt that online artifacts provided disembodied information so that strangers became acquaintances, eliminating the temporal and spatial barriers of offline interactions and providing information that was usually not revealed during FTF interactions. Then, by recalling the personas of others on the virtual stage, the respondents were better able to define a situation and adjust their expectations of others in FTF interactions.

\section{Revealing hidden information}

Another important reason identified by respondents was that online artifacts gave them access to information that was usually hidden during FTF interaction. During FTF interactions, it is not only necessary to obtain information about others to decide how to proceed, but also essential to gauge the "real" attitudes or motives of others (Goffman 1959). In this regard, the respondents also felt that access to online artifacts helped to differentiate between "real" and "fake”, and "authentic" and "performative”, which consequently allowed more accurate judgment of the "real” others, and reduced the uncertainties of interpersonal interaction. Thus, many of the respondents mentioned that the effects of online artifacts were not always meant to cultivate friendships, but also to avoid interactions.

I think I know them better [after viewing online profiles and posts]. But it’s not necessarily a good thing because sometimes I don't think much of them [based on their artifacts]. Like some people post too many status updates...(or) show off by showing that they stayed at a pricey hotel or went to some fancy restaurant. That's kind of shallow and I don't think I want to be friends with them. (Mainland interview 17, female)

In offline interactional contexts, information that is obtained by relying on paralinguistic cues, body language, and specific physical properties, such as social distance (Goffman 1959; Bell 
1984; Grice 1975; Labov 1966/2006) reflects and contributes to how our audience is defined and degree of interaction with them. However, it seems that there is now less reliance on offline cues and more on online artifacts to define a situation, as elaborated by a male student:

I frequently check others’ information online, both strangers or someone I met once, or people that I think I might want to know in the future. I look them up before and after our real life interaction. Then that information determines my attitude toward them the next time that we meet. For example, I check out their Facebook page...so when we meet, I know whether I should give respect to this person... if they are worthy, I try to establish some commonality with them... I might put on the charm and hope they like me...people who I don't like or have nothing that I want, then I'll avoid them or try not to get to know them well, even though they might have left a good impression in real life. I think that this way, I have more confidence in real life interactions. (Mainland interview 39, male)

This student intentionally sought others’ online artifacts to determine his demeanor and the amount of deference he showed during their FTF interactions. This student felt access to others' online profiles increased his confidence during FTF interactions because the online artifacts helped him decide how to define the situation and how to act, and many others in this study shared his sentiment.

It is already well known, and the study respondents also acknowledged this phenomenon that users might present idealized selves or "hoped-for possible selves” on social media (Zhao et. al. 2008; Yurchisinet al., 2005). However, the study respondents indicated that they could differentiate authentic from fabricated information, which is consistent with findings that people believe they can make accurate judgments of others based on online artifacts (Vazire and 
Gosling 2004) by differentiating between information given and given off online. Online self presentations largely rely on text (Robinson 2007; Menchik and Tian 2008), but just like offline contexts, information is "given” and "given off” through text (Robinson 2007). Consequently, viewers feel that they can differentiate authentic from fabricated by evaluating online expressions "given off".

This was especially true regarding political views. During the interviews, the respondents said that mainland students had different viewpoints on the various events related to the recent Hong Kong-Mainland China conflicts. In daily FTF interactions, they rarely discussed politics, so their social-political stance was not made clear. However, once others were added as online contacts, their updates and feeds were visible, which allowed their social-political viewpoints to surface. A female student explained how this affected her partiality:

The worst are those who post opinions that I don't agree with ... some are very pro-China, others are very pro-democracy. This was most obvious during the Occupy Central Movement last year. Some posted very extreme views...In fact...I blocked them afterwards. I wouldn't want contact with them in real life either. I only found out about their attitudes from their WeChat Moments. We never talk about those topics when we meet. It's rare. Maybe once and between me and my very best friend. (Mainland interview 47, female)

Another male respondent echoed his view:

I met this guy who seemed nice and friendly. We both joined the same student association and had a few meals together. He behaved like a normal person and the conversation was ok. But during the Occupy Movement last year, I found out that he has 
extreme views. He criticized local Hong Kong students online, saying that they are stupid because the movement wasn't going to change anything. I don't like people saying things like that. So I blocked him from my contact list and since then I've avoided him in person. (Mainland interview 36, male)

As shown, social-political views expressed as online artifacts were risky. Technology and the interactional venue made information available to interactants that were normally unavailable in an immediate physical interactional context, so both commonalities and differences were visible or even magnified prior to direct engagements offline.

It is also interesting that in the event of a discrepancy between online and offline impressions, online artifacts were considered by the students to be more accurate and authentic.

If someone says something on his/her Renren or Facebook, it must be true, or at least s/he means it...Because if not, his/her friends would have said something. For example, if a guy tells you that he is dating a girl on his Facebook, it must be true. But if he tells you in real life, he could just be showing off. (Mainland interview 2, female)

In fact, almost all of the respondents indicated that good offline impressions were not sufficient enough to perpetuate an offline relationship. Poor online impressions not only deterred friendships from the beginning, but also changed the nature of the interaction.

Indeed, these students had good reason to believe that online artifacts were more reliable because nowadays, social actors attempt to construct and present a coherent image both online and offline. According to Davis (2014), social actors not only balance their ideal-authentic images across multiple arenas, they also actively construct their selves to make them consistent 
with their profiled data. Moreover, online artifacts are created collaboratively across multiple sites (both online and offline) and multiple media (Davis2010; Gonzales and Hancock 2011). This is especially true given that many social media allow continuous updates to profile data, so new information about how one acts in different situations is constantly being provided. Social media cultivates the creation of artifacts through self-generated information and information generated by friends and systems (Tong et al. 2008; Utz 2010). This ability to access how others have performed over time and across different situations leads interactants to trust in the online profiled self rather than an offline person who is performing in only one setting at one particular time. Recollection of the personas of other people on the virtual stage therefore has a more important role than interpretations made in the physical context.

Yet some of the respondents admitted that this precedence accorded to online artifacts only applied to acquaintances and casual friends. The offline impressions of close friends were still paramount because frequent and long-term FTF interaction meant that they already knew how their close friends had performed across different occasions over time. They were even able to identify the reasons for discrepancies should they occur. For example, one student said, "he (best friend) said stupid things on WeChat because his mom was reading”.

In sum, the respondents felt that online artifacts facilitated offline interpersonal interactions. Their previous exposure to online artifacts gave them a sense of control in interpersonal interactions, allowing them to choose the right topics of conversation or individuals with whom to carry out offline interactions. Most importantly, online artifacts could nullify the significance of many signals and cues that were once useful in constructing interpretations in FTF interactions. However, while the respondents attempted to use online artifacts to control offline encounters, to reduce uncertainties, and to gauge their "real" attitudes or motive, uncertainty remained. This 
uncertainty was rooted in the unique social organization of online interactions, as will be discussed next.

\section{N-ADIC INTERACTION AND MISMATCHED EXPECTATIONS}

According to Tian and Menchik (2016), when a user posts on social media, there is uncertainty whether his/her contacts have actually seen the posting or when they saw the posting, unless feedback is provided. Since most users merely lurk, they are invisible to the owners of online artifacts. The $n$-adic structure of online interaction can lead to two scenarios related to online artifacts that have the potential to create inconsistent selves and consequently embarrassment.

Scenario one usually takes place before breaches occur (see Figure 1). Profile owners may consider their online artifacts as information shared with only their chorus members, but neglect the influential outsiders who incorrectly think that it is appropriate for discussion during offline encounters.

In the last few months, I frequently updated information on my relationship with my boyfriend on WeChat Moments...he’s...kind of needy...(and) needs me to show that I'm thinking about him all the time. So I post a lot of our updates and pictures...(but) only for him and his friends to see...one day, my Hong Kong friend suddenly brought up my pictures (in a FTF encounter)...I didn’t know what to say...didn’t think my Hong Kong friends would see them...so embarrassed. (Mainland interview 50, female)

The awkward situation was thus caused by misinterpretation; the profile owner thought that her online artifacts were only shared with the chorus members. However, since influential outsiders also had access to the content, they thought that they were included in the dialogue. This led to 
mismatched expectations about what or how much the influential outsider knew about the profile owners. Consequently, when the profile owner found out that an influential outsider knew more than she had expected, she felt embarrassed because “contextual integrity” of information was compromised (Nissenbaum 2010), while the influential outsider was unaware of a problem.

Temporality also plays a role here. In $n$-adic interaction, others may enter a past interaction even when the interaction is over; this can lead to problems in FTF encounters, as illustrated in the following:

I was talking to this girl at lunch. She said something,....I then quoted one of her comments on Renren to argue with her. She denied that she had ever said anything like that. Then I pulled out my phone and found the Renren post on her page. It was a feed that she had posted a year ago. She...got very angry. After that, she never spoke to me again and pretended that she didn’t know me....(Mainland interview 8, male)

Here, the FTF interaction ended unpleasantly because a past disclosure was brought into the current interaction. Previously, past disclosures were stored elsewhere and difficult to locate but in the digital age, the wide use of search engines and Web 2.0 platforms allows the personal information of ordinary people to be instantly available to millions of individuals (Zimmer and Hoffman 2011).

After a few breaches, users began to assume that their online artifacts were shared with everyone, including influential outsiders. In fact, many of the study respondents admitted that after a few breaches, they began to self-censor and only posted information that could be shared with "anyone". However, assuming everyone on the contact list would see the posting could also result in misunderstandings and embarrassment: 
During a small gathering (with Mainland Chinese students), I brought up another student and his girlfriend. All of a sudden, it got very quiet and awkward. I found out later that they had actually broken up and it was one of the hottest and most debated topics on Renren. Everyone knew...But not me. He must have thought that I brought it upon purpose to humiliate him. He got so mad...But I really didn’t know. (Mainland interview 5 , female)

The male student in the above scenario was angry and embarrassed because the self whom he was trying to project (a respectable student who studies at an elite university and gets along well with his peers) could not be sustained in harmony with another self (someone involved in a nasty breakup). As Goffman predicted, both the individual whose self was threatened (the male student) and the individual who caused this threat (the female respondent) felt embarrassed about the situation (Goffman 1963: 106).

Misunderstandings can also happen when online artifacts disclose achievements of pride:

I was talking to this freshman. He wasn’t very respectful so I got a little bit angry...He thought I was only here for graduate school. ${ }^{4}$ So I told him that I did my undergraduate at this university as well...to show that I did better than him in the college entrance examination. His attitude towards me obviously changed afterwards...I was surprised. After adding me onto his Facebook and WeChat, I expected that he would have read my background information. (Mainland interview 22, female)

\footnotetext{
${ }^{4}$ Mainland students who are in Hong Kong for their undergraduate studies are usually considered to be intellectually outstanding because they scored high on the national college examination in China. However, those who only enroll in graduate school in Hong Kong may not have done as well on the exam. Also, the admission scores for Mainland Chinese students entering Hong Kong universities were higher a couple of years ago, which means those who were admitted then are considered more exceptional than those admitted more recently.
} 
This respondent assumed that her online contacts would read her postings, which was not true in this case and consequently, the individual failed to behave in an appropriate way; that is, to demonstrate respect to a more senior student with high academic ability. During interviews, many other respondents shared similar incidents. For example, another male student recalled meeting a friend on campus, whom he greeted as usual, yet the friend seemed to react negatively. This student found out later online that his friend just won a major prize, and thus attributed the friend's unhappiness to his lack of congratulations, stating "He must think I was jealous, or not happy about his achievements” (mainland interview 27, male).

Ultimately, the central issue is the amount of control over the dissemination of online artifacts. Due to the uncertainty about what is being shared and with whom, the participants in interactions are likely to have mismatched expectations about how much other people know about them. Mismatched expectations lead to embarrassment and thus disrupt the interaction order. Figure 2 summarizes how the different levels of awareness of online audiences disrupt the FTF interaction order.

$<$ Figure 2 here $>$

Even worse, mismatched expectations mean that it is more difficult to identify discrepancies between online and offline images. Embarrassment is a social emotion and can only be alleviated by others who are engaged in ongoing interactions; they provide support to sustain one’s performance(Goffman 1963). However, in some instances, interactants realize that embarrassment has been caused due to facial expressions or body language, but since the cause of the embarrassment cannot be readily identified at that moment, there is no alleviation, as demonstrated by the examples above. 
Over time, the respondents in this study began to realize the issues related to online disclosures, and tried to control the amount of information available on them. At least one third of the respondents admitted to regularly deleting their previous WeChat Moments postings because they did not want to give new acquaintances so much information about their past. Around $80 \%$ also tried to control individuals who viewed their postings by using the "group" function in WeChat, which allowed them to share postings with only a select group of contacts.

\section{CONCLUSION AND DISCUSSION}

In this paper, I focus on "disembodied information": social cues that are not in the immediate interactional context, but have been previously made available to interactants through social media. The artifacts from social media are important for FTF interactions because when personal data are known prior to specific offline encounters, they change how participants define the FTF situation. To interpret ongoing FTF interactions, participants rely less on embodied information gathered in the physically and temporally bounded context, and more on disembodied information, or recollections of performances of others on the virtual stage. By demonstrating that FTF interactions are now disembedded from the local context, this research asserts that profound changes are instigated by the Internet's reconfigurations of spatial and temporal constraints.

Thus, the key issue is the amount of control perceived versus the actual amount of control in the digital era. While existing research has examined the loss of control on online platforms, the focus is on privacy and oversharing, i.e. with unintended others (Belk 2013; Marwick and boyd 2011; Zimmer and Hoffman 2011). However, the findings from this study suggest that even if 
the intended audience is "anyone on my contact list", that is, even influential outsiders, there will still be misunderstandings and loss of control. Indeed, oversharing is just one aspect; lack of control also includes the false assumption that information is publicly known. Therefore, when users might be confident that they have more control over their self-presentation or identity construction on social media, new forms of uncertainties are simultaneously created, which are caused by the unique structure of online interaction with undetectable others. When coupled with the asynchronicity of interaction, these new forms of uncertainties obscurity lead to mismatched expectations about whether certain information should be limited or known widely, which ultimately results in disruption of the interaction order.

This research work shows that online artifacts are both positive and negative for FTF interactions, if it is assumed that the purpose of interactions is for interactants to perform in a way that is desirable to themselves. Easy access to the increasing volume of online artifacts makes it possible to gather more information about others, and reduce uncertainty and exert more control during FTF encounters. However, it also increases ambiguity about how much personal information is available to others, largely due to the $n$-adic structure of online interaction. To be sure, disembodied information existed long before the Internet; however, there are key differences between disembodied information now and prior to the advent of the Internet in terms of access ease, volume, scope, and temporality. The sheer richness and depth of information available now are unimaginable before the Internet. Furthermore, once an interaction happened, it became past history. However, with social media, actors can easily delve into a past episode, so that disembodied information given off in the distant past can still be relevant and valid for current interactions. 
The findings from this study also suggest that sometimes easy access to online artifacts can cause individuals to avoid FTF encounters with those with conflicting online artifacts. The Internet can expose divergent perspectives (Kahne et al. 2012), even if such information is not intentionally sought, but only passively viewed through social media postings. Controversial postings, rather than broadening views, result in avoidance of further direct contact.

This study suggests that a significant change instigated by new information and communication technologies is the rise of disembodied information about ordinary people, which has fundamentally changed the relevance of past encounters and disclosures in contemporary society. Traditionally, all past performances matter; current actions were a continuation of past performances, due to familiarity or close networks and ties. In modern society this is not the case due to increased interactions with strangers or semi-strangers. Yet the ease of access to online artifacts has changed this, as Belk (2013) stated, "search engines and social media also help us remember other people, emotions, and events of significance in our lives” (p488-489).Past performance now becomes relevant in current interpersonal interaction even in a modern society where people frequently interacting with unfamiliar others. 
Figure 1. Gradual Awareness of Multiple Audiences

Perception of Audience

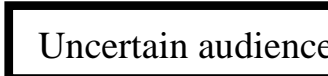

Regular

feedback

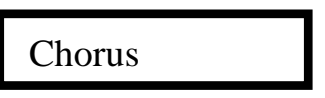

Breaches

Influential outsiders

\section{Online Disclosures}

little personal or sensitive information

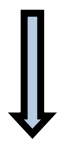

$\Longrightarrow \quad$ exchange of sensitive and personal information

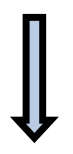

fewer disclosures, privacy control measures 
Figure 2: Awareness of online disclosure and impacts on FTF interactions

Scenario 1: Owner thinks online artifacts are only shared with chorus members

\begin{tabular}{|c|c|c|}
\hline & Online artifact owner & Influential outsider \\
\hline $\begin{array}{l}\text { Assumptions about } \\
\text { online artifacts }\end{array}$ & $\begin{array}{l}\text { I am only sharing with chorus } \\
\text { members. }\end{array}$ & $\begin{array}{l}\text { I have access to your online } \\
\text { artifacts; therefore, I am } \\
\text { included in the online } \\
\text { discussion. }\end{array}$ \\
\hline $\begin{array}{l}\text { Expectations for } \\
\text { disembodied } \\
\text { information during an } \\
\text { FTF encounter }\end{array}$ & $\begin{array}{l}\text { I do not assume that you know about } \\
\text { my online artifacts. }\end{array}$ & $\begin{array}{l}\text { You know I already know } \\
\text { about your online artifacts. }\end{array}$ \\
\hline $\begin{array}{l}\text { Consequences in FTF } \\
\text { encounters }\end{array}$ & Surprise, embarrassment & $\begin{array}{l}\text { I do not know why you are } \\
\text { embarrassed. }\end{array}$ \\
\hline
\end{tabular}


Scenario 2: Owner thinks online artifacts are shared with everyone, including influential outsiders.

\begin{tabular}{|c|c|c|}
\hline & Online artifact owner & Influential outsider \\
\hline $\begin{array}{l}\text { Assumptions about } \\
\text { online artifacts }\end{array}$ & $\begin{array}{l}\text { I am sharing with all my social media } \\
\text { contacts. }\end{array}$ & $\begin{array}{l}\text { I have access to your online } \\
\text { artifacts, but I haven't read } \\
\text { them yet. }\end{array}$ \\
\hline $\begin{array}{l}\text { Expectations for } \\
\text { disembodied } \\
\text { information during an } \\
\text { FTF encounter }\end{array}$ & $\begin{array}{l}\text { You have access to my online } \\
\text { artifacts, so you know about my past } \\
\text { and are familiar with my online } \\
\text { image. }\end{array}$ & $\begin{array}{l}\text { I do not know that you expect } \\
\text { me to know so much about } \\
\text { your past. }\end{array}$ \\
\hline $\begin{array}{l}\text { Consequences in FTF } \\
\text { encounters }\end{array}$ & Surprise, embarrassment & $\begin{array}{l}\text { I do not know what I did } \\
\text { wrong. }\end{array}$ \\
\hline
\end{tabular}




\section{References:}

Bell, Allan. 1984. “Language Style as Audience Design.” Language in Society (13): 145-204.

Belk, W. Russell. 2013. “Extended Self in a Digital World.” Journal of Consumer Research 40 (3): 477-500.

Berger, Charles R., and Richard J. Calabrese. 1975. "Some Explorations in Initial Interaction and Beyond: Toward a Developmental Theory of Interpersonal Communication." Human Communication Research 1: 99-112.

boyd, danah. 2008. "Why Youth (Heart) Social Network Sites: The Role of Networked Publics in Teenage Social Life.” Pp. 199-242 in Youth, Identity and Digital Media, edited by D. Buckingham. Cambridge, MA: MIT Press.

Campos-Castillo, Celeste and Steven Hitlin. 2013. “Copresence: Revisiting a Building Block for Social Interaction Theories.” Sociological Theory 31(2): 168-192.

Chow, Vivienne. 2012. “Anger at Mainland Visitors Escalates with 'Locust' Ad.” South China Morning Post, February 1. Retrieved February 01, 2016 (http://www.scmp.com/article/991355/anger-mainland-visitors-escalates-locust-ad).

Davis, Jenny L. 2010. “Architecture of the Personal Interactive Homepage: Constructing the Self through MySpace.” New Media \& Society 12: 1103-19.

—. 2014. “Triangulating the Self: Identity Processes in a Connected Era.” Symbolic Interaction 37 (4): 500-523.

Davis, Jenny L. and Nathan Jurgenson. 2014. “Context Collapse: Theorizing Context Collusions and Collisions.” Information, Communication \& Society 17(4): 476-485. 
Debatin, Bernhard, Jennette P. Lovejoy, Ann-Kathrin Horn and Brittany N. Hughes. 2009. "Facebook and Online Privacy: Attitudes, Behaviors, and Unintended Consequences.” Journal of Computer-Mediated Communication 15(1): 83-108.

Denzin, Norman K. 2001. Interpretive Interactionism.Thousand Oaks, CA: Sage Publications.

Ellis, Carolyn. 1995. Final Negotiations: A Story of Love, Loss, and Chronic Illness. Philadelphia: Temple University Press.

Emerson, Robert. 2015. Everyday Troubles: The Micro-Politics of Interpersonal Conflict. Chicago: University of Chicago Press.

Gardner, Carol Brooks and William P. Gronfein. 2005. "Reflections on Varieties of Shame Induction, Shame Management, and Shame Avoidance in Some Works of Erving Goffman.”Symbolic Interaction 28(2) (Spring 2005): 175-182.

Giddens, Anthony. 1987. Social Theory and Modern Sociology. Cambridge: Polity Press. Goffman, Erving. 1959. The Presentation of Self in Everyday Life. New York, NY: Anchor Books.

- 1961. Encounters: Two Studies in the Sociology of Interaction. New York, NY: Macmillan.

1963. Behavior in Public Places:Notes on the Social Organization of Gatherings. New York: Free Press of Glencoe.

Goldenberg, Sheldon. 1993. “Analytic Induction Revisited.” The Canadian Journal of Sociology.18(2): 161-176. 
Gonzales, Amy L. and Jeffrey T. Hancock. 2011. "Mirror, Mirror on My Facebook Wall: Effects of Exposure to Facebook on Self-Esteem.” Cyberpsychology, Behavior and Social Networking 14: 79-83.

Gosling, Samuel, Adam A. Augustine, Simine Vazire, Nicholas Holtzman, and Sam Gaddis. 2011. "Manifestations of Personality in Online Social Networks: Self-Reported Facebookrelated Behaviors and Observable Profile Information.” Cyberpsychology, Behavior and Social Networking 14(9): 483-488.

Grice, H. Paul. 1975. “Logic and Conversation.” Pp. 41-58 in Syntax and Semantics, Volume 3: Speech Acts, edited by J. P. Kimball. New York: Academic Press.

Hall, Jeffrey A., Natalie Pennington, and Allyn Lueders. 2014. "Impression Management and Formation on Facebook: A Lens Model Approach.” New Media and Society 16 (6): 958-982.

Heath, Christian. 1988. “Embarrassment and Interactional Organization.” Pp.136-160 in Erving Goffman: Exploring the Interaction Order, edited by P. Drew and A. Wooton. Cambridge: Polity.

Hogan, Bernie. 2010. "The Presentation of Self in the Age of Social Media: Distinguishing Performances and Exhibitions Online.” Bulletin of Science, Technology \& Society 30(6): 377-386.

Kahne, Joseph, Ellen Middaugh, Nam-Jin Lee, and Jessica T. Feezell. 2012. "Youth Online Activity and Exposure to Diverse Perspectives.” New Media \& Society 14(3): 492-512.

Katz, Jack. 2001. “Analytical Induction.” Pp. 480-84 in International Encyclopedia of the Social and Behavioral Sciences,vol. 1, edited by N. J. Smelser and P. B. Baltes. Oxford, England: Elsevier.

Labov, William. 1966. The Social Stratification of English in New York City (2nd ed.). 
Cambridge: Cambridge University Press.

Lai, Alexis. 2012. “Hong Kong Newspaper Ad Rails Against Chinese 'Invasion'.”CNN,8 Feb, Retrieved February 1, 2016 (http://edition.cnn.com/2012/02/01/world/asia/locustMainlander-ad/).

Litt, Eden. 2012. “Knock, Knock. Who's There? The Imagined Audience.”Journal of Broadcasting \& Electronic Media 56(3): 330-345.

Maloney, Patricia. 2013. “Online Networks and Emotional Energy: How Pro-Anorexic Websites Use Interaction Ritual Chains to (Re)form Identity.” Information, Communication \& Society 16(1): 105-124.

Marwick, Alice. E. and danah boyd. 2011. "I Tweet Honestly, I Tweet Passionately: Twitter Users, Context Collapse, and the Imagined Audience.” New Media \& Society 13(1): 114133.

2014. "Networked Privacy: How Teenagers Negotiate Context in Social Media.” New Media and Society 16 (7): 1051-1067.

Menchik, Daniel and Tian Xiaoli. 2008. "Putting Social Context into Text: The Semiotics of Email Interaction.” American Journal of Sociology 114(2): 332-370.

Murphy, Elizabeth and Robert Dingwall. 2003. Qualitative Methods and Health Policy Research. New York: Aldine de Gruyter.

Nissenbaum, Helen. 2010. Privacy in context: Technology, policy, and the integrity of social life. Stanford, CA: Stanford University Press. 
Ragin, C. Charles and Lisa, M. Amoroso. 2010. Constructing Social Research: The Unity and Diversity of Method. SAGE Publications.

Robinson, Laura. 2007. “The Cyberself: The Self-ing Project Goes Online, Symbolic Interaction in the Digital Age.”New Media \& Society 9(1): 93-110.

Schwartz, Raz and Germaine R. Halegoua. 2014. "The Spatial Self: Location-Based Identity Performance on Social Media.” New media \& Society.Retrieved February 1, 2016 (http://nms.sagepub.com/content/early/2014/04/09/14614444814531364.abstract).

Simmel, George. 1971. On Individuality and Social Forms. Chicago: Univ. of Chicago Press. Tharoor, Ishaan. 2014. “Chinese Toddler Pees in Hong Kong Street, Stirs Online Firestorm.” Washington Post, April 30. Retrieved February 1, 2016 (http://www.washingtonpost.com/blogs/worldviews/wp/2014/04/30/chinese-toddler-pees-inhong-kong-street-stirs-online-firestorm/).

Tian, Xiaoli. 2016. "Network Domains in Social Networking Sites: Expectations, Meanings, and Social Capital.” Information, Communication \& Society. 19 (2): 188-202.

Tian, Xiaoli and Daniel Menchik (2016). “On Violating One’s Own Privacy: How N-adic Utterances Lead to InadvertentDisclosures Online.” Studies in Media and Communication.11: 3-31.

Timmermans, Stefan and Iddo Tavory. 2012. “Theory Construction in Qualitative ResearchFrom Grounded Theory to Abductive Analysis.”Sociological Theory.30(3):167-186.

Tong, Stephanie Tom, Brandon Van Der Heide, Lindsey Langwell, and Joseph B. Walther. 2008. "Too Much of a Good Thing? The Relationship Between Number of Friends and Interpersonal Impressions on Facebook.” Journal of Computer-Mediated 
Communication13(3): 531-549.

Tönnies, Ferdinand. 1963[1965]. Community \&Society. New York: Harper \& Row.

Utz, Sonja. 2010. "Show Me YourFriends and I Will Tell You What Type of a Person You Are:

How One’s Profile, Number of Friends, and Type of Friends Influence Impression

Formation on Social Network Sites.” Journal of Computer-Mediated Communication 15:

314-335.

Vazire, Simine and Samuel D. Gosling. 2004. "E-Perceptions: Personality ImpressionsBased on

Personal Websites.”Journal of Personality and Social Psychology 87: 123-132.

Westerman, David, Brandon Van Der Heide, Katherine A. Klein, and Joseph B. Walther. 2008.

"How do People Really Seek Information about Others? Information Seeking Across

Internet and Traditional Communication Channels.” Journal of Computer-Mediated

Communication 13: 751-767.

Yee, Nick, Jeremy N. Bailenson and Nicolas Ducheneaut. 2009. “The Proteus Effect:

Implications of Transformed Digital Self-Representation on Online and Offline Behavior.'

Communication Research 36(2): 285-312.

Yurchisin, Jennifer, KittichaiWatchravesringkanand Deborah B. McCabe. 2005. “An

Exploration of Identity Re-creation in theContext of Internet Dating.” Social Behavior and

Personality 33(8), 735-750.

Zhao, Shanyang. 2005. "The Digital Self: Through the Looking Glass of Telecopresent.”

Symbolic Interaction 28(3):387-405.

Zhao, Shanyang, Sherri Grasmuck and Jason Martin. 2008. "Identity Construction on Facebook:

Digital Empowerment in Anchored Relationships.”Computers in Human Behavior 24: 18161836. 
Zimmer, Michael and Anthony Hoffman. 2011. "Privacy, Context, and Oversharing:

Reputational Challenges in a Web 2.0 World.” Pp. 175-184in The Reputation Society: How Online Opinions are Reshaping the Offline World,editedbyH. Masum and M. Tovey.

Cambridge, Mass.: MIT Press. 